\title{
Psoriasin (S100A7) increases the expression of ROS and VEGF and acts through RAGE to promote endothelial cell proliferation
}

Emman Shubbar, Jenny Vegfors, Maria Carlström, Stina Petersson and Charlotta Enerbäck

\section{Linköping University Post Print}

N.B.: When citing this work, cite the original article.

The original publication is available at www.springerlink.com:

Emman Shubbar, Jenny Vegfors, Maria Carlström, Stina Petersson and Charlotta Enerbäck, Psoriasin (S100A7) increases the expression of ROS and VEGF and acts through RAGE to promote endothelial cell proliferation, 2012, Breast Cancer Research and Treatment, (134), 1, 71-80.

http://dx.doi.org/10.1007/s10549-011-1920-5

Copyright: Springer Verlag (Germany)

http://www.springerlink.com/?MUD=MP

Postprint available at: Linköping University Electronic Press

http://urn.kb.se/resolve?urn=urn:nbn:se:liu:diva-76132 
Psoriasin (S100A7) increases the expression of ROS and VEGF and acts through RAGE to promote endothelial cell proliferation

Emman Shubbar ${ }^{1}$, Jenny Vegfors $^{2}$, Maria Carlström ${ }^{2}$, Stina Petersson ${ }^{2}$ and Charlotta Enerbäck $^{2}$

${ }^{1}$ Department of Clinical Genetics, Sahlgrenska University Hospital, SE-413 45 Gothenburg, Sweden; ${ }^{2}$ Department of Clinical and Experimental Medicine, Division of Cell Biology and Dermatology, Linköping University, SE-581 85 Linköping, Sweden

Correspondence: Charlotta Enerbäck, Department of Clinical and Experimental Medicine, Division of Cell Biology and Dermatology, Linköping University, SE-581 85 Linköping, Sweden. Tel. +46 10 1037429. Fax.+46 10 1031708. E-mail: charlotta.enerback@liu.se 


\section{ABSTRACT}

Psoriasin (S100A7), originally identified in psoriasis, is a calcium-binding protein belonging to the multigenic S100 family. In high-grade ductal carcinoma in situ (DCIS), psoriasin was identified as one of the most abundant transcripts. We have previously shown that psoriasin was induced by reactive oxygen species (ROS). Moreover, the downregulation of psoriasin by short hairpin RNA (shRNA) led to the reduced expression of VEGF and inhibited tumour growth in vivo. The aim of the present work was to investigate whether psoriasin could have direct effects on endothelial cells. Here, we demonstrated that psoriasin increased VEGF expression in mammary epithelial cells. The treatment of endothelial cells with recombinant psoriasin increased proliferation comparable to that of recombinant VEGF protein. No change in proliferation was seen when endothelial cells were infected with psoriasin-expressing adenoviruses, suggesting that the proliferative effect of psoriasin was mediated by a specific receptor. Treatment with sRAGE, targeting the receptor for advanced glycation end products (RAGE), thus inhibited endothelial cell proliferation and tube formation enhanced by recombinant psoriasin. We showed that VEGF expression was not induced by hydrogen peroxide, when psoriasin was silenced by shRNA, which led to the hypothesis that psoriasin induces ROS. Indeed, psoriasin was shown to induce ROS in both endothelial and epithelial cells. Moreover, sRAGE inhibited the psoriasin-dependent generation of ROS in endothelial cells. Finally, treatment with antioxidant Bcl-2 protein abolished the effect of psoriasin on endothelial cell proliferation.

Our data suggest that psoriasin expression in mammary epithelial cells leads to increased endothelial cell proliferation in a paracrine manner through RAGE. Psoriasin may therefore play a role in breast cancer progression by promoting oxidative stress response and angiogenesis.

Keywords: Psoriasin/S100A7; Angiogenesis; RAGE; VEGF; ROS; Breast Cancer. 


\section{INTRODUCTION}

Tumour growth and metastasis are processes known to require neovascularisation. As a result, angiogenesis has been intensively studied in the context of tumour growth. It is a complex, multistep process involving extracellular matrix remodelling, endothelial cell migration and proliferation, loop formation, capillary differentiation, anastomosis and finally lumen development [1]. While the vasculature is usually quiescent in adult tissue and tightly regulated by the balance of pro- and anti-angiogenic signals in normal tissues, this process is often deregulated in cancer, which is important for neoplastic progression [2]. Among the growth factors involved in tumour angiogenesis, vascular endothelial growth factor (VEGF) has been identified as a leading pro-angiogenic candidate [3]. The production of VEGF is controlled through the cellular response to low oxygen levels (hypoxia) which activate the transcription of VEGF by increasing the formation of reactive oxygen species (ROS) [4-5]. Moreover, VEGF mRNA levels were shown to be markedly increased in ductal carcinoma in situ (DCIS) and invasive breast carcinoma, compared with normal breast tissue [6-7].

In high-grade DCIS, which is an early clinical diagnosis of breast cancer, psoriasin (S100A7) was shown to be markedly upregulated [8-9]. The expression of psoriasin was shown to correlate with features of poor prognosis, including estrogen receptor (ER) and progesterone receptor (PR) negativity, HER2 positivity and the presence of lymphocytic infiltration [9-11]. Recently, we demonstrated that psoriasin correlates negatively with Intercellular adhesion molecule 1 (ICAM-1) and positively with Mucin1 (MUC1) [12]. Similar to VEGF we have previously demonstrated that psoriasin is induced by ROS [13]. In addition, we have shown that the downregulation of endogenous psoriasin expression in the MDA-MB-468 breast cancer cell line by short hairpin RNA (shRNA) inhibited tumor growth in vivo. In accordance with these findings, we demonstrated the downregulation of VEGF in cells with reduced psoriasin levels [14]. These findings raised the hypothesis that psoriasin may increase tumour 
growth by promoting angiogenesis. In the present study, we investigated whether psoriasin could have direct effects on endothelial cells. In fact, we demonstrated that psoriasin was able to induce human endothelial cell proliferation through the receptor for advanced glycation end products (RAGE) and the generation of ROS. In addition, we demonstrated that psoriasin upregulated VEGF in epithelial cells. These findings prove a direct link between psoriasin and angiogenesis.

\section{MATERIAL AND METHODS}

\section{Cell lines and culture conditions}

The human immortalized normal breast epithelial cell line, MCF10A, and the human breast cancer cell line, MDA-MB-468, were obtained from American Type Culture Collection and cultured as previously described [9]. The Human Umbilical Vein Endothelial Cells (HUVECs), obtained from Cascade Biologics, were grown in Medium 200 supplemented with LSGS. Neonatal human dermal microvascular endothelial cells (HMVEC-d), a kind gift from Dr Max Levin (Sahlgrenska University Hospital, Gothenburg, Sweden), were grown in endothelial growth medium (EGM) supplemented with EGM-2-MV (Lonza). A stable psoriasin-expressing cell line was established by infecting MCF10A cells with recombinant retrovirus overexpressing psoriasin [13]. The establishment of a stable clone with downregulated psoriasin expression was made by transfecting MCF10A with shRNA directed against human psoriasin, as previously described [14-15].

To examine the effect of intracellular psoriasin, MCF10A and HUVECs were infected with recombinant adenoviruses, as previously described [13]. Confluence culture was achieved by maintaining the cells in the confluent condition for 10 days. For suspension cultures, cells were plated into poly-2-hydroxy-ethylmethacrylate (polyHEMA) (Sigma Aldrich, P-3932) coated $\left(10 \mathrm{mg} / \mathrm{cm}^{2}\right.$ in $95 \%$ ethanol) Petri dishes for 3 days. Hydrogen peroxide $\left(\mathrm{H}_{2} \mathrm{O}_{2}\right)$ 
(Sigma-Aldrich, H-1009) was added to a final concentration of 75-225 $\mu \mathrm{M}$ in HBSS and incubated for 1 hour. The cells were then allowed to recover in regular medium for 5 days. Tumor necrosis factor-alpha (TNF- $\alpha$ ) (Sigma-Aldrich, T-6674) was added to a final concentration of $5 \mathrm{ng} / \mathrm{ml}$ and incubated for 24 hours. HUVECs were treated with various concentrations of recombinant psoriasin protein (Abnova) $(0.15-10 \mu \mathrm{g} / \mathrm{ml}$ ) or with recombinant VEGF protein (Invitrogen, PHC9394) $(10 \mathrm{ng} / \mathrm{ml})$ for 24 and 48 hours. HUVECs were visualized using a Leica DMRXA Widefield Microscope (Leica Microsystems Inc.). To investigate the effect of RAGE on cell proliferation, HUVECs were treated with an antiRAGE antibody (20 $\mu \mathrm{g} / \mathrm{ml}$ for 3 hours) (Millipore, MAB5328) or soluble RAGE (sRAGE) (50 ng/ml for 30 minutes) (R\&D Systems, 1145-RG).

\section{Purification of recombinant psoriasin protein}

Psoriasin cDNA inserted into the pQE30 expression vector was kindly provided by Dr. Kornelia Polyak, at the Dana-Farber Cancer Institute, in Boston. This vector was transformed into E. coli strain M15 (Qiagen, Inc.). The expression of recombinant 6xHis-tagged psoriasin in E.coli, carrying pQE30-psoriasin, was induced with Isopropyl $\beta$-D-1-thiogalactopyranoside (IPTG). The recombinant psoriasin protein was purified using NI-NTA agarose beads (Qiagen, Inc.) according to the manufacturer's instructions. Psoriasin was visualized by coommassie blue staining using a FluorChem 8000 camera (Alpha Innotech). Commercially available recombinant psoriasin protein (Abnova Corp., H00006278-P01) was also used in this study. Experiments were performed using commercially recombinant psoriasin protein, if $\underline{\text { not otherwise stated. }}$

RNA extraction, cDNA synthesis and quantitative Real-Time PCR (qRT-PCR) 
Total RNA was prepared using the RNeasy mini-kit (Qiagen, Inc., 74104). mRNA were converted to cDNA using SuperScript II RNase H-reverse Transcriptase (Invitrogen, 18.064014) or Maxima First Strand cDNA Synthesis Kit 200 rxn (Fermentas, K1642), according to the manufacturer's instructions. The expression was analyzed with qRT-PCR, performed on a real-time 7500 HT sequence detection system (Applied Biosystems), with the SYBR green detection system (Applied Biosystems). The primers for psoriasin, VEGF, $\beta$-actin and GAPDH, have been previously described [14,16-18]. The primer set for RAGE is forward, 5'ACGGCTGGTGTTCCCAATAA-3', and reverse 5'-TGTTCCTTCACAGATACTCCCTTC$3^{\prime}$. GAPDH or $\beta$-actin was used as endogenous reference gene. The relative expression of psoriasin, VEGF and RAGE was determined in relation to the expression in the control.

\section{Western blotting}

Western blotting was performed as previously described [19] and analysis were produced with anti-psoriasin (mouse-Ab) (Imgenex, IMG-409) and anti-GAPDH (rabbit-Ab) (Santa Cruz Biotechnology, sc-25778). Imaging analysis was performed with Alpha Ease FC Software.

\section{Flow cytometry}

A total number of $3 \times 10^{5}$ cells were suspended in PBS and incubated with anti-RAGE (mouse-Ab) (Millipore, MAB5328) $(1 \mu \mathrm{g} / \mathrm{ml})$ for $60 \mathrm{~min}$. Antibody binding was evidenced by $\underline{\text { FITC-conjugated secondary antibody (1:20) (goat anti-mouse) (Caltag Laboratories). Flow }}$ cytometry was performed to quantify the fluorescence intensity using the FACSAria (BD Biosiences). 
A NBT assay (Sigma-Aldrich, N5514) was performed as previously described [20]. The absorbance was measured at $630 \mathrm{~nm}$ using the Mithras LB940 instrument (Berthold Technologies).

\section{Cell viability and proliferation}

Cell proliferation was estimated using a CellTiter $96^{\circledR}$ AQueous One Solution Cell proliferation assay (MTS) (Promega, G3582), according to the manufacturer's instructions. The activity of cellular dehydrogenases was measured by adding the tetrasodium salt MTS to $\underline{\text { the cells. Viable cells reduce the MTS tetrazolium salt into a soluble formazan product. The }}$ quantity of formazan was measured by the amount of absorbance at $490 \mathrm{~nm}$ using the Mithras $\underline{\text { LB940 Instrument (Berthold Technologies) and is directly proportional to the number of }}$ viable cells in proliferation. Moreover, cell proliferation was confirmed by trypan blue exclusion.

\section{Tube formation assay}

The formation of HUVECs in capillary-like structures was studied on Geltrex reduced growth factor basement membrane matrix (Invitrogen) in 24-well plates according to manufacturer's instructions. Cells were visualised after 18 hours of incubation using an Olympus IX51 inverted microscope and a PC-connected Olympus DP70 camera.

\section{Statistical analysis}

Data were analyzed for statistical significance by Student`s $t$-test (one-tailed). $\mathrm{p}<0.05$ was considered statistically significant. The values presented are an average of at least three independent experiments. Each independent experiment was performed at least in triplicate, if not otherwise stated. 


\section{RESULTS}

Psoriasin increases VEGF expression in mammary epithelial cells

To investigate the effect of the upregulation of psoriasin on the expression of VEGF, we utilized adenoviral vector-mediated transient expression as well as retroviral vector-mediated stable expression of psoriasin in the normal breast epithelial cell line, MCF10A. As shown in Figure 1a, the upregulation of psoriasin at the mRNA level led to the significant upregulation of VEGF mRNA. A suspension culture of MCF10A cells, a condition we have previously demonstrated to induce high endogenous psoriasin levels [9], also showed an increased expression of VEGF mRNA. This suggests that both exogenous and endogenous psoriasin expression is associated with increased VEGF expression in mammary epithelial cells.

Next, we suppressed the low endogenous level of psoriasin in MCF10A cells with shRNA targeting psoriasin mRNA. We confirmed the downregulation of psoriasin expression in the MCF10A psoriasin-shRNA cells compared with MCF10A control-shRNA (C-shRNA) cells after treatment with different concentrations of hydrogen peroxide $\left(\mathrm{H}_{2} \mathrm{O}_{2}\right)$, a stimulus known to induce high endogenous psoriasin levels (Figure 1b). As shown in Figure $1 \mathrm{c}, \mathrm{H}_{2} \mathrm{O}_{2}$ led to the upregulation of VEGF mRNA in the MCF10A C-shRNA cells. In contrast, in MCF10A psoriasin-shRNA cells, the induction of VEGF mRNA was significantly reduced. Thus, psoriasin increases the expression of VEGF in mammary epithelial cells.

We investigated the expression of psoriasin in HUVECs using different stimuli that induce psoriasin in mammary epithelial cells. In contrast to the epithelial cells, HUVECs treated with $\mathrm{H}_{2} \mathrm{O}_{2}$, TNF- $\alpha$ or cultured in suspension or confluence condition did not express psoriasin (data not shown). 


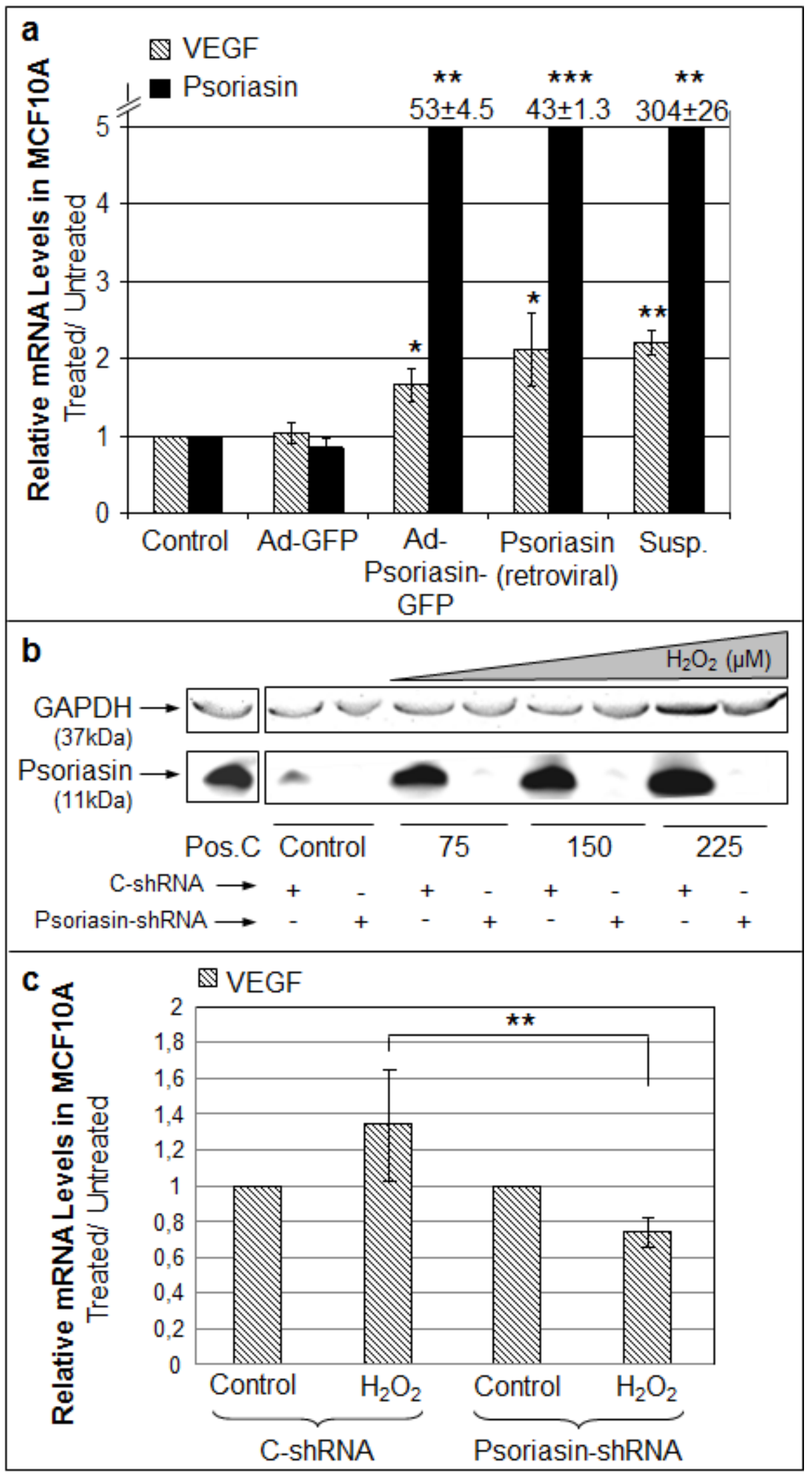

Fig. 1 Psoriasin increases VEGF expression in normal mammary epithelial cells (a) The expression of VEGF and psoriasin mRNA was significantly increased in MCF10A cells infected with psoriasin-expressing adenovirus (Ad-Psoriasin-GFP) or psoriasin-expressing 
retrovirus, compared with control cells. An adenovirus carrying only the GFP gene served as a negative control (Ad-GFP). The same results were observed in suspension culture, a condition that induces endogenous psoriasin. (b) The shRNA-mediated downregulation of psoriasin in MCF10A was confirmed by treating MCF10A C-shRNA and psoriasin-shRNA cells with $\mathrm{H}_{2} \mathrm{O}_{2}$ at different concentrations (75-225 $\mu \mathrm{M}$ ) for 1 hour, after which cells were left to grow for a further 5 days. Psoriasin expression was not elevated in psoriasin-shRNA cells compared with C-shRNA cells, using Western blotting. MDA-MB-468 was used as a positive control (Pos.C) and GAPDH evaluates equal loading. The blots have been cropped. (c) MCF10A C-shRNA and psoriasin-shRNA cells were treated with $150 \mu \mathrm{M} \mathrm{H}_{2} \mathrm{O}_{2}$ for 1 hour and left to grow for a further 5 days. Using qRT-PCR, the upregulation of VEGF mRNA was verified in $\mathrm{H}_{2} \mathrm{O}_{2}$-treated MCF10A C-shRNA cells. The VEGF mRNA level was not induced after $\mathrm{H}_{2} \mathrm{O}_{2}$ treatment in psoriasin-shRNA cells compared with treated C-shRNA cells. The mRNA expression data for VEGF and psoriasin are presented as ratios, in which the expression data are normalized to $\beta$-actin (a) and GAPDH (c) as an internal control. Untreated cells were designed as 1 and treated cells, from the same experiment, were normalized to this. The data are expressed as mean \pm SD. The p-values $(*<0.05, * *<0.01, * * *<0.001)$ were calculated using a one-tailed $t$-test.

\section{Extracellularly administered psoriasin triggers proliferation of endothelial cells}

We and others have shown that psoriasin is secreted from epithelial cells $[9,20]$. We hypothesized that psoriasin secreted from mammary epithelial cells may lead to endothelial cell proliferation. To address this, HUVECs were treated with various concentrations of recombinant psoriasin for 24 hours. As shown in Figure 2a, psoriasin significantly induced HUVEC proliferation, with the maximum effect at $0.15 \mu \mathrm{g} / \mathrm{ml}$, using the MTS assay. Extending the length of the treatment to 48 hours did not increase HUVEC proliferation (data not shown). The effect of psoriasin was comparable to that of recombinant VEGF, used as a positive control for HUVEC proliferation (Figure $2 \mathrm{~b}$ and $2 \mathrm{c}$ ). The figures show that both VEGF and psoriasin promoted HUVEC proliferation as compared to untreated control cells. The effect of psoriasin was also tested in HMVEC-d cells using the MTS assay. As shown in Figure 2d, psoriasin significantly increased HMVEC-d proliferation as compared to the untreated control. The proliferation of HUVEC and HMVEC-d in response to psoriasin was confirmed using trypan blue exclusion (data not shown). These data confirm the effect of psoriasin on proliferation in two distinct endothelial cell types. 


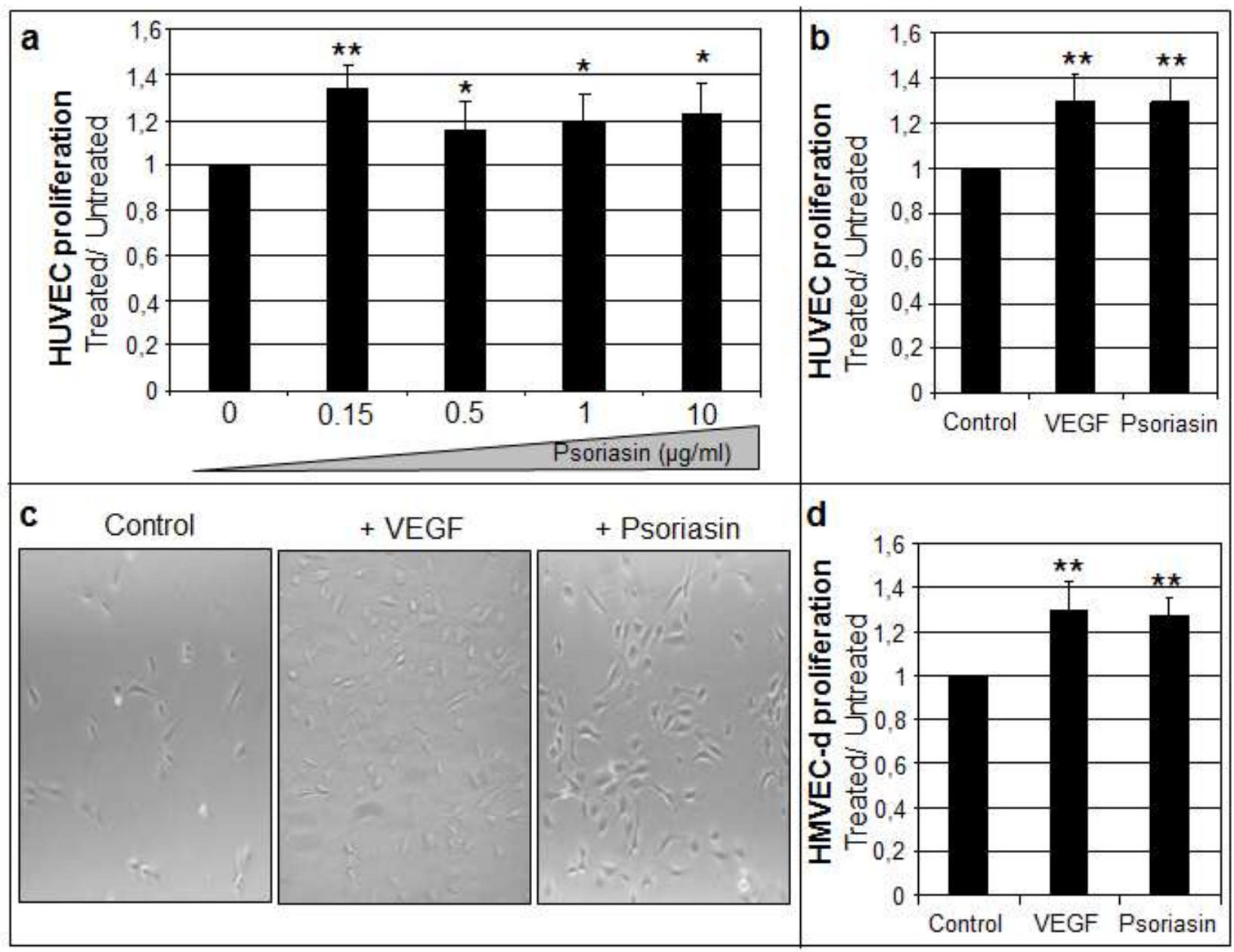

Fig. 2 Extracellularly administered recombinant psoriasin protein increases the proliferation of endothelial cells (a) Treatment with various concentrations of in laboratory made recombinant psoriasin protein $(0.15-10 \mu \mathrm{g} / \mathrm{ml})$ for 24 hours significantly increased the proliferation of HUVECs with maximum effect at $0.15 \mu \mathrm{g} / \mathrm{ml}$. (b) Proliferation after treatment with psoriasin $(0.15 \mu \mathrm{g} / \mathrm{ml}$ for 24 hours $)$ was comparable to that seen for VEGF-stimulated cells $(10 \mathrm{ng} / \mathrm{ml}$ for 24 hours). (c) Microscopic pictures of HUVECs treated with recombinant VEGF and psoriasin protein for 24 hours. (d) Treatment with VEGF $(10 \mathrm{ng} / \mathrm{ml})$ or psoriasin $(0.15 \mu \mathrm{g} / \mathrm{ml})$ for 24 hours significantly increased the proliferation of HMVEC-d cells. Proliferation was determined by the MTS assay. Untreated cells were designed as 1 and treated cells, from the same experiment, were normalized to this. The data are expressed as mean $\pm \mathrm{SD}$. The p-values $(*<0.05, * *<0.01)$ were calculated using a one-tailed $t$-test.

Extracellularly administered psoriasin triggers proliferation and tube formation of endothelial cells via RAGE

To further explore the proliferative effect of psoriasin in endothelial cells, HUVECs were treated with psoriasin-expressing adenovirus (Ad-Psoriasin-GFP), which led to the transient intracellular expression of psoriasin. As shown in Figure 3a, no change in proliferation was 
seen when cells were infected with psoriasin-expressing adenoviruses. This finding led to the hypothesis that the proliferative effect of psoriasin on endothelial cells may be mediated by a specific receptor present on endothelial cells.

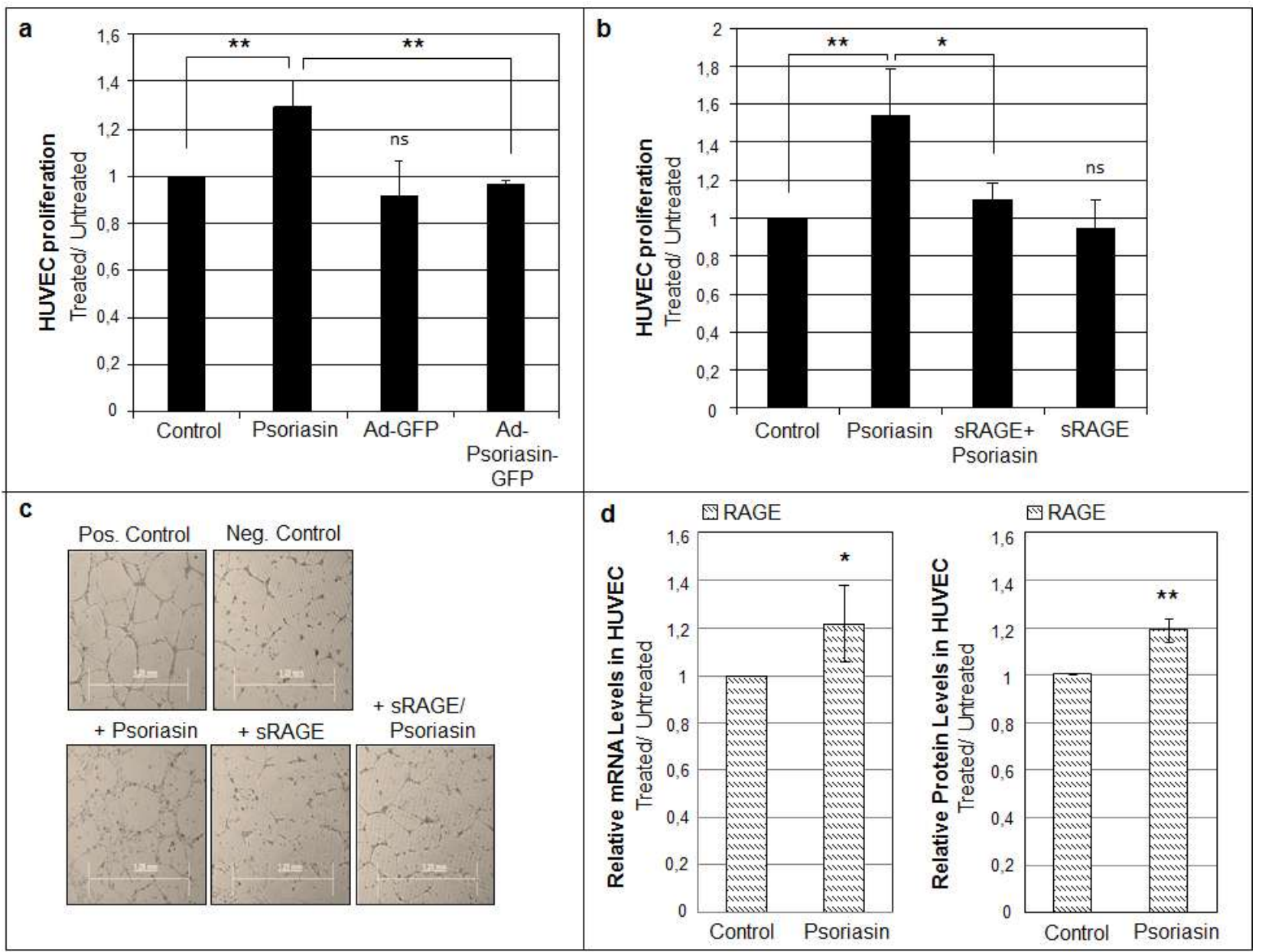

Fig. 3 Inhibition of RAGE diminishes endothelial cell proliferation and tube formation in response to recombinant psoriasin protein (a) HUVECs were infected with psoriasinexpressing adenovirus (Ad-Psoriasin-GFP). After 48 hours, HUVEC proliferation was comparable to that of the untreated control cells. (b) sRAGE significantly prevented HUVEC proliferation in response to psoriasin as compared to cells treated with recombinant psoriasin only. HUVEC proliferation was determined by the MTS assay. (c) The tube formation of HUVECs was induced by psoriasin $(10 \mu \mathrm{g} / \mathrm{ml})$. HUVECs treated with recombinant psoriasin in combination with sRAGE resulted in reduced tube formation. Control cells are grown with (Pos. Control) or without (Neg. Control) LSGS in medium. (d) Treatment with psoriasin $(0.15$ $\mu \mathrm{g} / \mathrm{ml}$ for 24 hours) significantly induced RAGE expression on mRNA and protein level in HUVECs, determined by qRT-PCR and flow cytometry, respectively. Untreated cells and cells treated with recombinant psoriasin, Ad-GFP, and sRAGE, served as controls. Untreated HUVECs were designed as 1 and treated HUVECs, from the same experiment, were normalized to this. The data are expressed as mean \pm SD. In figure $b$, experiments were performed in duplicate. The p-values $(*<0.05, * *<0.01)$ were calculated using a one-tailed $t$ test, ns indicate not statistically significant bars compared to control. 
RAGE belongs to the immunoglobulin superfamily and has been shown to be expressed on endothelial cells [21] and to be a putative receptor for several S100 proteins, including psoriasin [22-23]. We examined whether RAGE was involved in the cellular responses to psoriasin in endothelial cells by using the specific inhibitory effect of soluble RAGE (sRAGE), which contains the ligand binding domains, and an anti-RAGE antibody, which competes with the binding of ligands to RAGE. HUVECs were treated with sRAGE or antiRAGE prior to psoriasin treatment. As shown in Figure 3b, sRAGE significantly abrogated HUVEC proliferation in response to psoriasin treatment. Similarly, anti-RAGE treatment led to the decreased proliferation of HUVECs, although this effect did not reach statistical significance (data not shown). Furthermore, sRAGE reduced HUVEC tube formation, induced by recombinant psoriasin protein (Figure 3c). It is known that RAGE is expressed at low levels in normal tissues and becomes upregulated wherever its ligands accumulate. Extracellular psoriasin induced RAGE expression at mRNA and protein level (Figure 3d). This results support the notion that RAGE is a receptor for psoriasin. In conclusion, our data suggest that RAGE-mediated signaling is involved in psoriasin-induced endothelial cell proliferation and tube formation.

Psoriasin induces the proliferation of endothelial cells through the interaction with RAGE and ROS generation

It is known that ROS at low levels induces the proliferation of different cell types and specifically endothelial cells [24]. Both psoriasin [13] and VEGF [25] are induced by ROS. The finding that VEGF expression in epithelial cells is not induced by ROS when psoriasin is silenced by shRNA (Figure 1c) led to the hypothesis that psoriasin induces ROS. To address this issue, HUVECs were exposed to recombinant psoriasin $(0.15 \mu \mathrm{g} / \mathrm{ml})$. A significant induction of ROS generation was observed (Figure 4a). We also demonstrated that 
recombinant VEGF induce ROS in HUVECs. Higher concentrations of recombinant psoriasin $(0.5-10 \mu \mathrm{g} / \mathrm{ml})$ showed a significant induction of ROS generation in the same range as 0.15 $\mu \mathrm{g} / \mathrm{ml}$ psoriasin (data not shown). As demonstrated in Figure 4b, the generation of ROS is significantly reduced when HUVECs are incubated with sRAGE prior to psoriasin treatment. These findings suggest that psoriasin induces the proliferation of endothelial cells through interaction with RAGE and increased levels of ROS. To investigate whether the proliferative effect of psoriasin on endothelial cells can be explained by this mechanism, HUVECs were pretreated with adenoviral Bcl-2 protein (Ad-Bcl-2-GFP), an antioxidant protein, followed by treatment with recombinant psoriasin. As shown in Figure 4c, Bcl-2 efficiently prevented the enhanced HUVEC proliferation, supporting the hypothesis that psoriasin-mediated ROS generation stimulates endothelial cell proliferation.

\section{Endogenous psoriasin expression generates ROS in mammary epithelial cells}

To evaluate the generation of ROS by endogenous psoriasin in normal mammary epithelial cells, MCF10A cells with downregulated psoriasin by shRNA were treated with $\mathrm{H}_{2} \mathrm{O}_{2}$. As shown in Figure 5, ROS was generated in response to psoriasin induction in MCF10A CshRNA cells treated with $\mathrm{H}_{2} \mathrm{O}_{2}$ compared with untreated MCF10A cells. Importantly, ROS generation was significantly reduced in MCF10A psoriasin-shRNA cells with downregulated psoriasin expression after $\mathrm{H}_{2} \mathrm{O}_{2}$ treatment, supporting the hypothesis that psoriasin, previously known to be induced by ROS [13], generates ROS. 


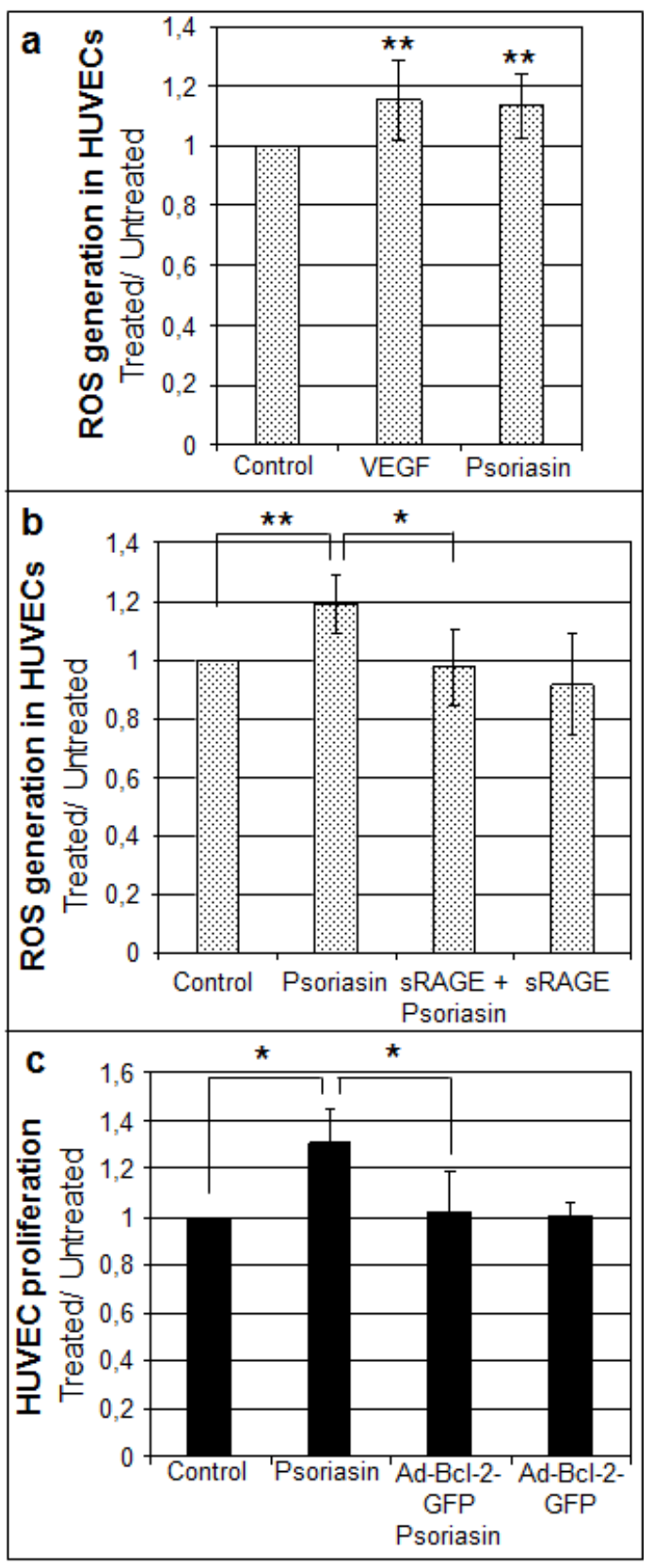

Fig. 4 Psoriasin induces the proliferation of endothelial cells through interaction with RAGE and increased levels of ROS (a) Treatment with VEGF (10 ng/ml for 24 hours) and psoriasin $(0.15 \mu \mathrm{g} / \mathrm{ml}$ for 24 hours) significantly increased the ROS generation in HUVECs. Four experiments were performed in duplicate. (b) HUVECs treated with sRAGE before the treatment with recombinant psoriasin protein displayed a significantly reduced ROS formation, compared with psoriasin-treated cells. Experiments were performed in duplicate. (c) HUVECs were infected with Bcl-2-expressing adenovirus (Ad-Bcl2-GFP), prior to the treatment with recombinant psoriasin, which led to a significant reduction in HUVEC proliferation. ROS formation in HUVECs was determined by the NBT assay and proliferation was determined by the MTS assay. Untreated HUVECs and HUVECs treated with VEGF, sRAGE and Ad-Bcl2-GFP served as controls. Untreated HUVECs were designed as 1 and treated HUVECs, from the same experiment, were normalized to this. The data are expressed as mean $\pm \mathrm{SD}$. The p-values $(*<0.05, * *<0.01)$ were calculated using a one-tailed $t$-test, $\underline{\mathrm{ns}}$ indicate not statistically significant bars compared to control. 


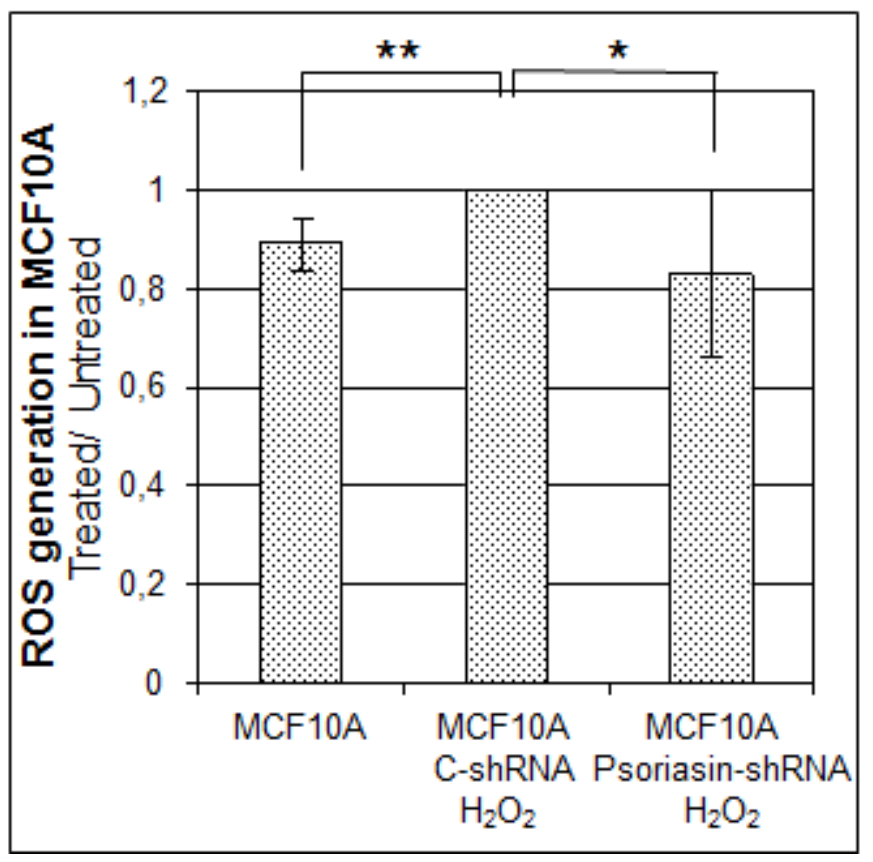

Fig. 5 The downregulation of psoriasin reduces ROS production in normal mammary epithelial cells The treatment of MCF10A psoriasin-shRNA cells with $\mathrm{H}_{2} \mathrm{O}_{2}$ led to a significantly repressed induction of ROS, compared with treated C-shRNA cells. $\mathrm{H}_{2} \mathrm{O}_{2}$-treated MCF10A C-shRNA cells were designed as 1 and MCF10A psoriasin-shRNA cells and MCF10A cells, from the same experiment, were normalized to this. In two out of four experiments untransfected MCF10A cells were used. The data are expressed as mean \pm SD. Experiments were performed in duplicate. The p-values $(*<0.05, * *<0.01)$ were calculated using a one-tailed $t$-test.

\section{DISCUSSION}

The progressive growth and metastasis of neoplasms, including breast cancer, depend on angiogenesis. VEGF is known as a multifunctional cytokine that plays a critical role in blood vessel formation including both vasculogenesis and angiogenesis [26]. VEGF promotes the induction of endothelial cell proliferation and capillary morphogenesis both in a paracrine mode, after its release by other cells, and in an autocrine manner in VEGF-producing endothelial cells [27]. In fact, the over-expression of VEGF has been regarded as a major factor underlying pathological angiogenesis in cancer, as well as in chronic inflammation, such as psoriasis [28].

We have previously shown that the downregulation of endogenous psoriasin expression in the MDA-MB-468 cell line by shRNA increased cell migration and invasion without influencing 
cell proliferation and survival in vitro but dramatically inhibited tumour growth in vivo, as assessed by tumour weight [14]. In line with these findings, we demonstrated an upregulation of matrix metalloproteinase 13 (MMP13) and a downregulation of VEGF in cells with reduced psoriasin levels. Moreover, we demonstrated a statistically significant positive correlation between psoriasin expression and blood vessel density, determined by the immunohistochemical analysis of psoriasin and CD31, an endothelial cell-specific marker [14]. These findings raised the hypothesis that psoriasin may increase tumour growth in vivo by promoting angiogenesis. Correlating with this hypothesis, high-grade comedo DCIS, which frequently over-express psoriasin, is associated with increased VEGF levels and angiogenesis [29]. We have demonstrated a strong positive association between psoriasin and VEGF expression levels following the exogenous and endogenous upregulation of psoriasin in normal mammary epithelial cells. To investigate to which extent VEGF induction was influenced by the lack of endogenous psoriasin induction in MCF10A cells we used shRNA specific for psoriasin. We showed that the downregulation of psoriasin reduced VEGF mRNA induction in MCF10A cells treated with $\mathrm{H}_{2} \mathrm{O}_{2}$.

We and others have demonstrated that psoriasin may be secreted by but also located in the cytoplasm and the nucleus of the cells expressing it [9,30]. To examine possible differences in extracellular and intracellular effects of psoriasin on endothelial cell proliferation, we treated endothelial cells with recombinant psoriasin protein and infected endothelial cells with psoriasin-expressing adenovirus. The proliferation of endothelial cells by extracellularly administered recombinant psoriasin was comparable to that seen for VEGF-stimulated cells. The lack of effect of intracellularly administered psoriasin led to the hypothesis that the proliferative effect may be mediated by a specific receptor.

RAGE is a multi-ligand receptor which recognizes ligands from diverse families, such as advanced glycation endproducts (AGEs), amphoterins, and S100/calgranulins [31]. RAGE 
transduces inflammatory responses and plays a role in the pathogenesis of several diseases including neurodegeneration, inflammation and cancer [32-33]. RAGE is able to bind a variety of structurally diverse ligands and the locations of RAGE upregulation tend to colocalize with molecules thought to bind to the receptor. Recently, RAGE was suggested as a putative receptor for some S100 proteins in the extracellular space [34]. S100A12 and S100B are well established as ligands of RAGE and, more recently, S100A8/A9 was shown to promote tumor cell growth via RAGE ligation [35]. Because of the common structural features and sequence homology among S100 proteins, we hypothesized that psoriasin was a putative ligand to RAGE in endothelial cells. It was recently shown that RAGE may mediate the psoriasin-mediated chemotaxis of leucocytes [22]. We demonstrated that, opposite to epithelial cells, psoriasin was neither expressed nor inducible in endothelial cells. We therefore predicted that psoriasin secreted from epithelial cells may interact with RAGE on the surface of endothelial cells, which may in turn induce endothelial cell proliferation and angiogenesis. To address this issue, we used a monoclonal antibody directed against the RAGE immunoglobulin domains (anti-RAGE) and sRAGE, a truncated form of the receptor spanning the extracellular domain of human RAGE, to inhibit the putative interaction between psoriasin and RAGE on the cell surface. Since sRAGE does not act on the receptor itself, but its ligands, treatment with sRAGE informs us of the consequences of reducing the bioavailability of the ligand as opposed to the consequences of preventing RAGE signal transduction [36]. By blocking RAGE-psoriasin interactions, a significant suppression of the psoriasin-induced increase in cell proliferation and tube formation were demonstrated. Based on our data, we suggest that psoriasin stimulates endothelial cell proliferation and tube formation through RAGE. The identification of RAGE as a receptor for psoriasin raises the possibility of targeting psoriasin-mediated effects. Moreover, the interaction between secreted 
psoriasin and RAGE contributes to our understanding of RAGE in promoting tumor progression [33].

ROS have been reported to induce VEGF synthesis in various cell types. $\mathrm{H}_{2} \mathrm{O}_{2}$ increased VEGF expression in keratinocytes [37] and in endothelial cells [38]. We have previously shown that psoriasin is induced by stress stimuli such as ROS [13]. Low levels of ROS may induce the proliferation of different cell types specifically endothelial cells [39]. In HaCaT keratinocytes overexpression of S100A8 and S100A9 promoted NADPH oxidase activation followed by higher levels of ROS generation [40]. We hypothesized that psoriasin may induce low levels of ROS by a similar mechanism, leading to a further increase in ROS levels, VEGF expression and cell growth. In fact, psoriasin was shown to induce ROS in endothelial cells. Moreover, when treating epithelial cells with $\mathrm{H}_{2} \mathrm{O}_{2}$ the level of ROS was reduced in cells with downregulated psoriasin demonstrating the role of psoriasin in ROS generation. It has previously been demonstrated that the interaction of RAGE with its ligands may generate ROS [41]. Interestingly, we found that sRAGE significantly eliminated ROS generation in endothelial cells after treatment with psoriasin, further suggesting that RAGE acts as a receptor for psoriasin.

To verify the role of psoriasin-dependent ROS production in endothelial cell proliferation by extracellular psoriasin protein, we cultured endothelial cells in the presence of Bcl-2, an antioxidant protein. We found that Bcl-2 significantly reduced the cell proliferation induced by psoriasin, supporting the hypothesis that endothelial cell proliferation by psoriasin is mediated by ROS.

ROS leads to a wide range of cellular functions, from proliferation to cell death, and these responses rely mostly on differences in the amount and duration of ROS production. Typically, low doses of ROS stimulate cell proliferation, whereas severe oxidative stress causes cell death [42]. It has been demonstrated that small amounts of ROS are produced after 
cell stimulation with a variety of hormones and growth factors, including VEGF, following binding to cell membrane receptors [43]. Low concentrations of ROS may even mimic the action of growth factors [44]. Interestingly, the increase in intracellular ROS levels by extracellular psoriasin was in the same range as that previously demonstrated for S100B [45].

\section{Taken together, we have demonstrated that psoriasin contribute to the expression of ROS and}

VEGF and acts through RAGE to promote endothelial cell proliferation. A summary of the results is illustrated in figure 6. The high expression of psoriasin in high-grade DCIS, which is likely to be hypoxic, with elevated levels of ROS and VEGF, makes psoriasin an interesting candidate marker for angiogenesis. Thus, psoriasin may play a role in breast cancer progression by promoting oxidative stress response and angiogenesis. Our data raise the possibility that psoriasin may be evaluated as a novel anti-angiogenic target in breast cancer.

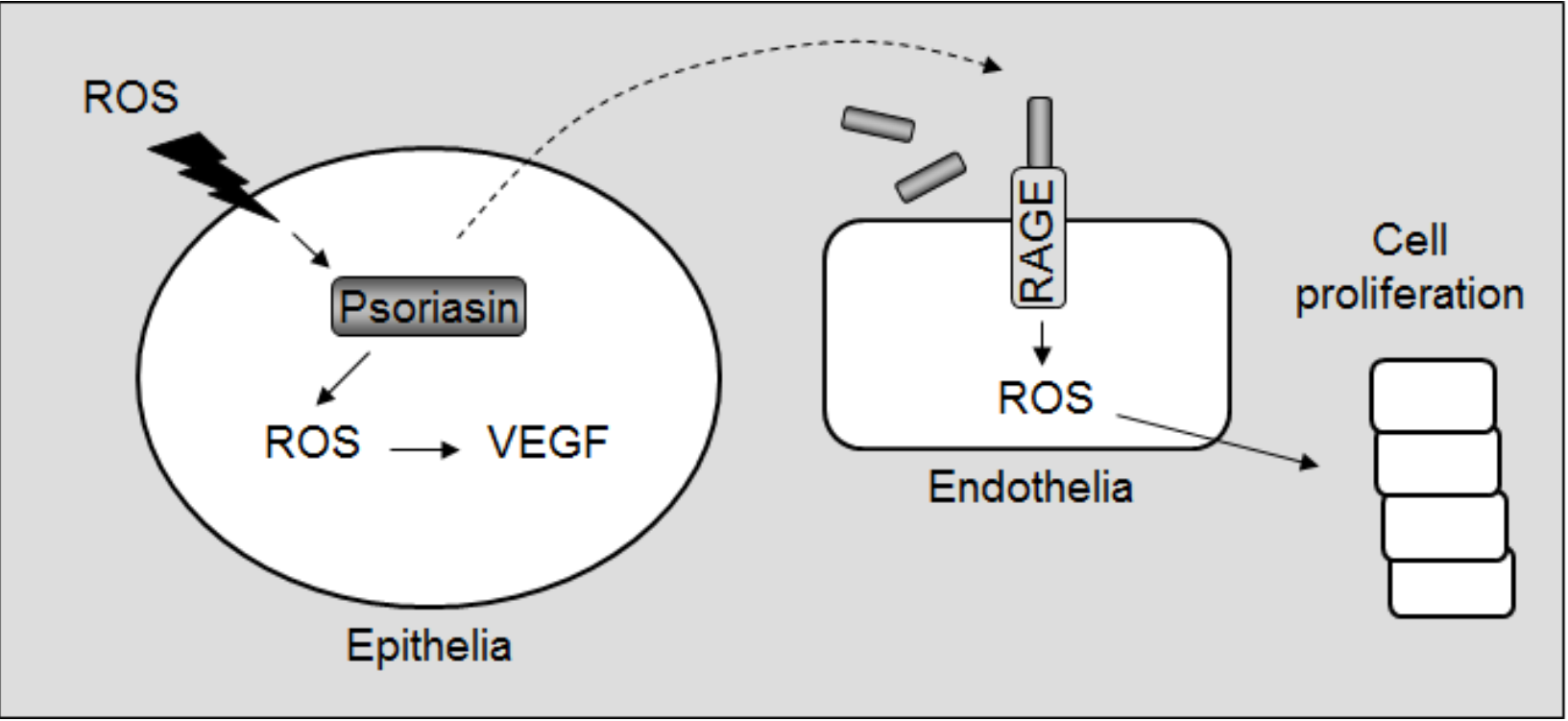

Fig. 6 Psoriasin promotes endothelial cell proliferation Psoriasin is induced by ROS and lead to further induction of ROS and VEGF in epithelial cells. Secreted psoriasin interacts with RAGE on endothelial cells which lead to ROS generation and endothelial cell proliferation. 


\section{ACKNOWLEDGEMENTS}

This work was supported by grants from the Swedish Cancer Society, the Swedish Psoriasis Association, the Assar Gabrielsson Foundation, the Welander Foundation and the Tore Nilsson Foundation.

\section{CONFLICT OF INTEREST}

The authors declare that they have no competing interests.

\section{REFERENCES}

1. Carmeliet P (2003) Angiogenesis in health and disease. Nat Med 9 (6):653-660. doi:10.1038/nm0603-653 nm0603-653 [pii]

2. Bergers G, Benjamin LE (2003) Tumorigenesis and the angiogenic switch. Nat Rev Cancer 3 (6):401-410. doi:10.1038/nrc1093 [doi] nrc1093 [pii]

3. Ferrara N, Davis-Smyth T (1997) The biology of vascular endothelial growth factor. Endocr Rev 18 (1):4-25

4. Liu Y, Cox SR, Morita T, Kourembanas S (1995) Hypoxia regulates vascular endothelial growth factor gene expression in endothelial cells. Identification of a 5' enhancer. Circ Res 77 (3):638-643

5. Chandel NS, Maltepe E, Goldwasser E, Mathieu CE, Simon MC, Schumacker PT (1998) Mitochondrial reactive oxygen species trigger hypoxia-induced transcription. Proc Natl Acad Sci U S A 95 (20):11715-11720

6. Yoshiji H, Gomez DE, Shibuya M, Thorgeirsson UP (1996) Expression of vascular endothelial growth factor, its receptor, and other angiogenic factors in human breast cancer. Cancer Res 56 (9):2013-2016

7. Lee AH, Dublin EA, Bobrow LG, Poulsom R (1998) Invasive lobular and invasive ductal carcinoma of the breast show distinct patterns of vascular endothelial growth factor expression and angiogenesis. J Pathol 185 (4):394-401. doi:10.1002/(SICI)10969896(199808)185:4<394::AID-PATH117>3.0.CO;2-S [pii]

10.1002/(SICI)1096-9896(199808)185:4<394::AID-PATH117>3.0.CO;2-S [doi]

8. Emberley ED, Murphy LC, Watson PH (2004) S100A7 and the progression of breast cancer. Breast Cancer Res 6 (4):153-159. doi:10.1186/bcr816

bcr816 [pii]

9. Enerback C, Porter DA, Seth P, Sgroi D, Gaudet J, Weremowicz S, Morton CC, Schnitt S, Pitts RL, Stampl J, Barnhart K, Polyak K (2002) Psoriasin expression in mammary epithelial cells in vitro and in vivo. Cancer Res 62 (1):43-47 
10. Emberley ED, Niu Y, Njue C, Kliewer EV, Murphy LC, Watson PH (2003) Psoriasin (S100A7) expression is associated with poor outcome in estrogen receptor-negative invasive breast cancer. Clin Cancer Res 9 (7):2627-2631

11. Watson PH, Leygue ER, Murphy LC (1998) Psoriasin (S100A7). Int J Biochem Cell Biol 30 (5):567-571. doi:S1357-2725(97)00066-6 [pii]

12. Petersson S, Shubbar E, Yhr M, Kovacs A, Enerback C (2010) Loss of ICAM-1 signaling induces psoriasin (S100A7) and MUC1 in mammary epithelial cells. Breast Cancer Res Treat. doi:10.1007/s 10549-010-0820-4

13. Carlsson H, Yhr M, Petersson S, Collins N, Polyak K, Enerback C (2005) Psoriasin (S100A7) and calgranulin-B (S100A9) induction is dependent on reactive oxygen species and is downregulated by Bcl-2 and antioxidants. Cancer Biol Ther 4 (9):998-1005. doi:1969 [pii]

14. Krop I, Marz A, Carlsson H, Li X, Bloushtain-Qimron N, Hu M, Gelman R, Sabel MS, Schnitt S, Ramaswamy S, Kleer CG, Enerback C, Polyak K (2005) A putative role for psoriasin in breast tumor progression. Cancer Res 65 (24):11326-11334. doi:65/24/11326 [pii] 10.1158/0008-5472.CAN-05-1523 [doi]

15. Masutomi K, Yu EY, Khurts S, Ben-Porath I, Currier JL, Metz GB, Brooks MW, Kaneko S, Murakami S, DeCaprio JA, Weinberg RA, Stewart SA, Hahn WC (2003) Telomerase maintains telomere structure in normal human cells. Cell 114 (2):241-253. doi:S0092867403005506 [pii]

16. Skliris GP, Lewis A, Emberley E, Peng B, Weebadda WK, Kemp A, Davie JR, Shiu RP, Watson PH, Murphy LC (2007) Estrogen receptor-beta regulates psoriasin (S100A7) in human breast cancer. Breast Cancer Res Treat 104 (1):75-85. doi:10.1007/s10549-006-9390-X [doi]

17. Sato T, Wu X, Shimogaito N, Takino J, Yamagishi S, Takeuchi M (2009) Effects of highAGE beverage on RAGE and VEGF expressions in the liver and kidneys. Eur J Nutr 48 (1):611. doi:10.1007/s00394-008-0753-4 [doi]

18. Doroudi R, Andersson M, Svensson PA, Ekman M, Jern S, Karlsson L (2005) Methodological studies of multiple reference genes as endogenous controls in vascular gene expression studies. Endothelium 12 (5-6):215-223. doi:L152627N9725486N [pii]

$10.1080 / 10623320500476377$

19. Petersson S, Bylander A, Yhr M, Enerback C (2007) S100A7 (Psoriasin), highly expressed in ductal carcinoma in situ (DCIS), is regulated by IFN-gamma in mammary epithelial cells. BMC Cancer 7:205. doi:1471-2407-7-205 [pii]

10.1186/1471-2407-7-205

20. Wadsworth TL, Bishop JA, Pappu AS, Woltjer RL, Quinn JF (2008) Evaluation of coenzyme Q as an antioxidant strategy for Alzheimer's disease. J Alzheimers Dis 14 (2):225234

21. Greten J, Kreis I, Wiesel K, Stier E, Schmidt AM, Stern DM, Ritz E, Waldherr R, Nawroth PP (1996) Receptors for advance glycation end-products (AGE) - expression by endothelial cells in non-diabetic uraemic patients. Nephrol Dial Transplant 11 (5):786-790

22. Wolf R, Howard OM, Dong HF, Voscopoulos C, Boeshans K, Winston J, Divi R, Gunsior M, Goldsmith P, Ahvazi B, Chavakis T, Oppenheim JJ, Yuspa SH (2008) Chemotactic activity of S100A7 (Psoriasin) is mediated by the receptor for advanced glycation end products and potentiates inflammation with highly homologous but functionally distinct S100A15. J Immunol 181 (2):1499-1506. doi:181/2/1499 [pii]

23. Hsieh HL, Schafer BW, Sasaki N, Heizmann CW (2003) Expression analysis of S100 proteins and RAGE in human tumors using tissue microarrays. Biochem Biophys Res Commun 307 (2):375-381. doi:S0006291X03011902 [pii] 
24. Luczak K, Balcerczyk A, Soszynski M, Bartosz G (2004) Low concentration of oxidant and nitric oxide donors stimulate proliferation of human endothelial cells in vitro. Cell Biol Int 28 (6):483-486. doi:10.1016/j.cellbi.2004.03.004 [doi]

S1065699504000599 [pii]

25. Kosmidou I, Xagorari A, Roussos C, Papapetropoulos A (2001) Reactive oxygen species stimulate VEGF production from $\mathrm{C}(2) \mathrm{C}(12)$ skeletal myotubes through a PI3K/Akt pathway. Am J Physiol Lung Cell Mol Physiol 280 (4):L585-592

26. Chen C, Li M, Chai H, Yang H, Fisher WE, Yao Q (2005) Roles of neuropilins in neuronal development, angiogenesis, and cancers. World J Surg 29 (3):271-275. doi:10.1007/s00268-004-7818-1 [doi]

27. Kyzas PA, Stefanou D, Batistatou A, Agnantis NJ (2005) Prognostic significance of VEGF immunohistochemical expression and tumor angiogenesis in head and neck squamous cell carcinoma. J Cancer Res Clin Oncol 131 (9):624-630. doi:10.1007/s00432-005-0003-6 [doi]

28. Claffey KP, Wilkison WO, Spiegelman BM (1992) Vascular endothelial growth factor. Regulation by cell differentiation and activated second messenger pathways. J Biol Chem 267 (23):16317-16322

29. Guidi AJ, Schnitt SJ, Fischer L, Tognazzi K, Harris JR, Dvorak HF, Brown LF (1997) Vascular permeability factor (vascular endothelial growth factor) expression and angiogenesis in patients with ductal carcinoma in situ of the breast. Cancer 80 (10):1945-1953. doi:10.1002/(SICI)1097-0142(19971115)80:10<1945::AID-CNCR11>3.0.CO;2-Y [pii]

30. Madsen P, Rasmussen HH, Leffers H, Honore B, Dejgaard K, Olsen E, Kiil J, Walbum E, Andersen AH, Basse B, et al. (1991) Molecular cloning, occurrence, and expression of a novel partially secreted protein "psoriasin" that is highly up-regulated in psoriatic skin. J Invest Dermatol 97 (4):701-712

31. Schmidt AM, Hofmann M, Taguchi A, Yan SD, Stern DM (2000) RAGE: a multiligand receptor contributing to the cellular response in diabetic vasculopathy and inflammation. Semin Thromb Hemost 26 (5):485-493. doi:10.1055/s-2000-13204 [doi]

32. Kuniyasu H, Oue N, Wakikawa A, Shigeishi H, Matsutani N, Kuraoka K, Ito R, Yokozaki H, Yasui W (2002) Expression of receptors for advanced glycation end-products (RAGE) is closely associated with the invasive and metastatic activity of gastric cancer. J Pathol 196 (2):163-170. doi:10.1002/path.1031 [pii]

10.1002/path.1031

33. Taguchi A, Blood DC, del Toro G, Canet A, Lee DC, Qu W, Tanji N, Lu Y, Lalla E, Fu C, Hofmann MA, Kislinger T, Ingram M, Lu A, Tanaka H, Hori O, Ogawa S, Stern DM, Schmidt AM (2000) Blockade of RAGE-amphoterin signalling suppresses tumour growth and metastases. Nature 405 (6784):354-360. doi:10.1038/35012626

34. Hofmann MA, Drury S, Fu C, Qu W, Taguchi A, Lu Y, Avila C, Kambham N, Bierhaus A, Nawroth P, Neurath MF, Slattery T, Beach D, McClary J, Nagashima M, Morser J, Stern D, Schmidt AM (1999) RAGE mediates a novel proinflammatory axis: a central cell surface receptor for S100/calgranulin polypeptides. Cell 97 (7):889-901. doi:S0092-8674(00)80801-6 [pii]

35. Ghavami S, Rashedi I, Dattilo BM, Eshraghi M, Chazin WJ, Hashemi M, Wesselborg S, Kerkhoff C, Los M (2008) S100A8/A9 at low concentration promotes tumor cell growth via RAGE ligation and MAP kinase-dependent pathway. J Leukoc Biol 83 (6):1484-1492. doi:jlb.0607397 [pii]

10.1189/jlb.0607397

36. Farmer DG, Kennedy S (2009) RAGE, vascular tone and vascular disease. Pharmacol Ther 124 (2):185-194. doi:S0163-7258(09)00140-5 [pii]

10.1016/j.pharmthera.2009.06.013 
37. Brauchle M, Funk JO, Kind P, Werner S (1996) Ultraviolet B and $\mathrm{H} 2 \mathrm{O} 2$ are potent inducers of vascular endothelial growth factor expression in cultured keratinocytes. J Biol Chem 271 (36):21793-21797

38. Chua CC, Hamdy RC, Chua BH (1998) Upregulation of vascular endothelial growth factor by $\mathrm{H} 2 \mathrm{O} 2$ in rat heart endothelial cells. Free Radic Biol Med 25 (8):891-897. doi:S0891584998001154 [pii]

39. Burdon RH (1995) Superoxide and hydrogen peroxide in relation to mammalian cell proliferation. Free Radic Biol Med 18 (4):775-794. doi:089158499400198S [pii]

40. Benedyk M, Sopalla C, Nacken W, Bode G, Melkonyan H, Banfi B, Kerkhoff C (2007) HaCaT keratinocytes overexpressing the S100 proteins S100A8 and S100A9 show increased NADPH oxidase and NF-kappaB activities. J Invest Dermatol 127 (8):2001-2011. doi:5700820 [pii]

10.1038/sj.jid.5700820

41. Yan SD, Schmidt AM, Anderson GM, Zhang J, Brett J, Zou YS, Pinsky D, Stern D (1994) Enhanced cellular oxidant stress by the interaction of advanced glycation end products with their receptors/binding proteins. J Biol Chem 269 (13):9889-9897

42. Martindale JL, Holbrook NJ (2002) Cellular response to oxidative stress: signaling for suicide and survival. J Cell Physiol 192 (1):1-15. doi:10.1002/jcp.10119

43. Abid MR, Tsai JC, Spokes KC, Deshpande SS, Irani K, Aird WC (2001) Vascular endothelial growth factor induces manganese-superoxide dismutase expression in endothelial cells by a Rac1-regulated NADPH oxidase-dependent mechanism. FASEB J 15 (13):25482550. doi:10.1096/fj.01-0338fje [doi]

01-0338fje [pii]

44. Sauer H, Diedershagen H, Hescheler J, Wartenberg M (1997) Calcium-dependence of hydrogen peroxide-induced c-fos expression and growth stimulation of multicellular prostate tumor spheroids. FEBS Lett 419 (2-3):201-205. doi:S0014-5793(97)01456-7 [pii]

45. Leclerc E, Fritz G, Weibel M, Heizmann CW, Galichet A (2007) S100B and S100A6 differentially modulate cell survival by interacting with distinct RAGE (receptor for advanced glycation end products) immunoglobulin domains. J Biol Chem 282 (43):31317-31331. doi:M703951200 [pii]

10.1074/jbc.M703951200 